\title{
Should the Dynamic Stochastic General Equilibrium (DSGE) Model be taught to Undergraduate Students of Economics?
}

\author{
Álvaro Moreno Rivas* \\ Translated by Enrique Ferrer-Corredor**
}

May be Yes. Maybe No. Maybe It does not matter.

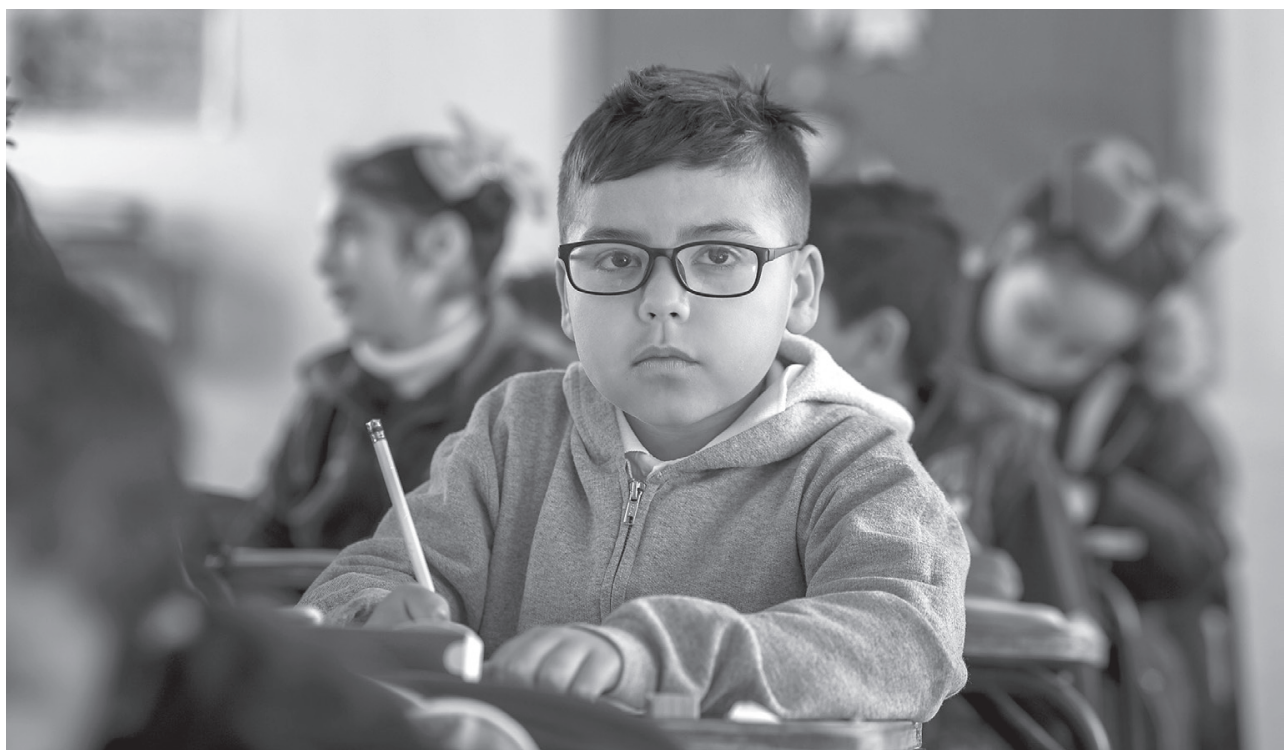

\begin{abstract}
In this article we present the consequences of introducing the advanced teaching of the DSGE (Dynamic Stochastic General Equilibrium) models to undergraduate economics programs. This monoculture leads to the deepening of the discipline insularity, to the disappearance of the paradigmatic plurality inside the economics departments and to the silencing of critical voices. This process obeys Gresham's Law of ideas: bad models displace good ideas.
\end{abstract}

Keywords: DSGE models, undergraduate macroeconomics, economic policy, modern macroeconomics

JEL: A22; E10; E60; E30

Citar este artículo como: Moreno Rivas, Á. (2018). Should the Dynamic Stochastic General Equilibrium (DSGE) Model be taught to Undergraduate Students of Economics? Revista Papeles, 10(19), 11-20.

* Associate professor at the National University of Colombia, and research professor at the Externado University. Email: amoreno65@yahoo.es

** Professor at Antonio Nariño University and National University of Colombia. 


\section{Introduction}

At the end of the third act of Milan Kundera's play Jacques and his Master (2005, p. 150), both characters are engaged in an enigmatic discussion. Jacques asks his Master to guide him forward, but he replies, "where is it?" Without hesitation, Jacques responds: "Go ahead is everywhere." Like all great literature, teaching is a shared journey, where the teacher and his disciples embark on an intellectual journey. Unfortunately, mainstream professors of economics ignore the "secular cunning of humanity": ahead is everywhere.

Young teachers of macroeconomics suffer from a high inter-temporal preference. They consider that the gap between the courses taught at undergraduate level and those taken in master's and doctoral programs should be closed quickly. They complain about the lack of rigor and foundational microeconomics of most intermediate textbooks and the persistence of the IS-LM model ${ }^{1}$. In response to this situation, some teachers of the discipline insist on the need to open a course in which future economists will be initiated at the core of modern macroeconomics, the DSGE models (Solis-Garcia, 2018; Torres, 2014; Costa Junior, 2016).

To defend this program and justify its teaching in undergraduate programs as the only alternative to reach the frontier of research is, clearly, an exercise in propaganda and intellectual sectarianism. Without doubt, there are other rigorously founded models whose analytical and conceptual richness compete in the same scenarios with the DSGE models. We refer to the models based on Post-Keynesian Heterogeneous Agents, the Stock-Flow models consisting of Godley and Lavoie (Veneziani and Zamparelli, 2018) and the macro-dynamic models derived from the great synthesis of Marx-Keynes-Schumpeter (Flaschel, 2009).

1 In general, two books are excepted: Barro (1986) and Williamson (2008).
Apparently there is an unmet demand that has to be covered. According to the apologists of the DSGE models, an introductory course in optimization and computation techniques and mathematics is justified from the perspective of the representative student for the following three reasons:

First, to help students work as close as possible to the frontier of macroeconomics research - students should have access to top journals and field articles- which are far from trivial. Second, to increase your human capital and improve your prospects after graduation. And finally, because deep in our hearts we hope that those students, when they are introduced to the frontier of modern macroeconomics, decide that a life of research is a life worth living and move to the exciting process of obtaining a $\mathrm{PhD}$ in economics. We can only dream (SolisGarcia, 2018, p. 227).

Macroeconomics teachers are moved by their candor. For them, schools of economics are just a continuum of homogeneous youthagents, whose preferences and restrictions define their decisions under competitive conditions and imperfect information. There is a friction that prevents boys and girls from accessing scientific knowledge of the frontier in macroeconomics.

The department director acts as a "benevolent dictator" who seeks to maximize the utility function of the students. In this sense, he designs strategies to correct the frictions that prevent the efficient allocation of individual talents. The market of ideas must resolve the lack of said asset.

The offer of a DSGE model course allows students to redefine their investment decisions in human capital, taking into account this new "option" that will not only improve their 
technical and conceptual skills, but also guarantees that the expected return more than compensates for the sacrifice of sleep, leisure and vagrancy in exchange for the long hours of formally difficult methodologies study. For their part, the economics schools will guarantee that their advanced postgraduate programs are filled with the best candidates. The offer creates its own demand. And the dream is consummated.

However, the world of "never ever" described by the DSGE models is not necessarily the best "option" to understand the functioning of the true capitalist economies. We should insist that the only thing that has to be taught is the neoclassical paradigm, or the so-called new macroeconomic consensus with all its technical filigree is to openly renounce pluralism in the departments of economy and, deepen the insularity of the economy (macroeconomics in particular), raising high retaining walls.

Important mainstream authors recognize that the DSGE models are erroneous and that what is required is to open the borders to other models and traditions that although survive in the low worlds of "academic resistance" also have mathematical and computational rigor (Blanchard, 2017; Haldane and Turrel, 2017). Time is perhaps the only truly scarce resource for an economics student. You cannot forget the golden rule of portfolio theory: "do not put all the eggs in one basket".

This article aims to show that what is sought with the introduction of a "border" course of DSGE models in undergraduate macroeconomics is practically to eliminate the theoretical and methodological pluralism of teaching. It is curious that economists do not take into account the problems of reducing teaching programs to a formal and analytical mono-culture that still does not respond adequately to the flaws present in its foundations and heuristic principles (Rogers, 2008).
It is worth mentioning the intellectual malaise that exists in an area as renowned as the theory of quantum gravity. After the consolidation of the theory of general relativity (GTR) and of quantum mechanics $(\mathrm{QM})$, theoretical physicists found themselves in need of searching for a theory that consistently integrated the GTR and QM (Rovelli, 1999).

The GTR radically transformed our conception of space and time, but maintained the Newtonian view of the relationship between the observer and the observed object. On the contrary, the QM left us without questioning the space-time ideas of classical physics, but changed the relations between the observer and the object of observation (Smolin, 2001).

Throughout the 20th century, three research programs emerged: string theory, quantum loop theory and twistor theory. Although the three theories have reported important advances in the project, the final theory is not yet available. However, string theory for various reasons was consolidated as the mainstream, displacing the other equally rigorous and respectable alternatives, causing a serious stagnation in the development of ideas and a long slowdown in the rate of new discoveries (Smolin, 2006). Something similar happens in the economic discipline with the DSGE models that constitute the new neoclassical synthesis that integrates the RBC models and the neo-Keynesian macroeconomics.

The article consists of four parts: the first is this introduction. The second presents the proposal and approach of a standard course of the frontier in macroeconomics of DSGE models. The third presents a model that simulates the disastrous consequences of teaching the models of Dynamic Stochastic General Equilibrium (DSGE) - as if it were the best economic theory- for the continuity of pluralism and the survival of critical voices in the economics departments. Finally, some brief conclusions are derived. 


\section{Cooking Gourmet DSGE models in an undergraduate course}

Perhaps the best way to understand the importance given by macroeconomics professors to the teaching of DSGE models is to compare this course with the learning of gourmet cuisine. Learning to cook is a task that requires effort and dense study. The evaluations are individual and reflect the ability to follow recipes and combine ingredients that surprise diners. To stand out, the student must be able to make small variations to the "core" recipe in order to obtain a differentiated dish. You can make mergers and innovations, but keeping the basic structure of the recipe and the steps of the preparation.

Learning how DSGE models are built is like learning to prepare a dish of "haute cuisine". You must master the technique, know the recipes and combine the ingredients to obtain a new dish that responds to the palate of the community of "border" macroeconomists.

The ingredients may vary, but do not leave the following: a continuum of consumer households whose preferences make them clones. A continuum of firms that face homogenous conditions of technology and that can act under conditions of perfect competition or monopolistic competition. A government or

\section{To stand out, the student}

must be able to make small

variations to the "core"

recipe in order to obtain

a differentiated dish. You

can make mergers and

innovations, but keeping

the basic structure of the

recipe and the steps of the

preparation. a central bank. Banks and the external sector can also be included. The sauces are varied and called "frictions"; that is, small wedges that prevent markets from functioning efficiently.

Depending on the type of model to be built, price flexibility is assumed or nominal or real rigidity is introduced, all to the consumer's taste. All agents solve optimization problems and it is assumed that they do so under the hypothesis of rational expectations. The models comply with the requirement of being micro-founded, of being of general equilibrium, of being dynamic and subject to exogenous stochastic disturbances.

You can learn all this program in a course of just 14 weeks, with three hours of reading and an hour and a half of laboratory per week. You only need to know the techniques of multivariate optimization under restrictions, to have passed the intermediate macroeconomics courses (Williamson, 2017; Mankiw, 2016). Although it would be good to have computer skills, it is not necessary.

The course proposed by Mario Solis-Garcia (2018) is as follows:

Weeks 1-2: Competitive Balance

Weeks 2-3: Solution of equations in MATLAB

Weeks 3-5: Dynamic Programming

Weeks 5-7: Log-linearization techniques

Weeks 8-10: Applications (Labor Offer, Fiscal Policy, other topics)

Weeks 11-13: Bayesian Econometrics, Calibration and Dynare

Weeks 13-14: Applications (Hansen model parameterization and Neo-Keynesian models)

Undoubtedly, the gourmet cooking course of DSGE models teaches how to cook DSGE models. Students will be convinced that the only thing worth cooking are DSGE models. Once they enter a $\mathrm{PhD}$ they will consider that the best way to obtain a laureate thesis is to 
cook a DSGE model and when they obtain a teaching position at a university, they will end up teaching DSGE models.

In the economics department nobody talks about anything other than DSGE models and whoever challenges the hegemony of the DSGE models will be pointed out as an agent who apparently did not make the correct investment. The "we" of the barracks and the religious seminary will expel the intruder. At that moment, the plurality of teaching and criticism of the academic discussion will have disappeared. Result: secular stagnation of the department.

Certainly, the success of this type of courses lies in the development of technical skills and abilities. Student's investment should be defined as a sunk cost; that is, it makes the decision irreversible. As the economists of the industrial organization say, "a barrier to entry becomes a barrier to exit". After a young person invests a large part of their resources and time in learning DSGE, it is practically impossible for them to deal with anything else and cynically dismiss the serious questions and problems of the basic theory that sustain them.

No one throws overboard what it has cost him so much to learn and will not hesitate to dismiss any criticism or questioning his work, prisoner of cognitive dissonance. As stated by Mark Setterfield (2018), an eminent professor of macroeconomics at the New School for Social Research:

Having reduced decision-makers to a single representative agent, modern mainstream macroeconomics also fails to heed lessons learned in general equilibrium theory over 40 years ago. The celebrated Sonnenschein-DebreuMantel (SDM) results show that the entire economy is unlikely to reflect the "well-behaved" properties assumed of individuals. In particular, if there is any heterogeneity among agents, then all bets are off as regards the uniqueness and stability of economy-wide equilibrium. The representative agent is thus revealed as evading rather than solving critical problems of aggregation (the relationship between parts and wholes), unless the economy is made up of a single Robinson- Crusoe-like figure or, alternatively, a plurality of clones (it isn't). None of this would have been news to Keynes, Mitchell, or any of the architects of the structural macroeconomics (then or now) that DSGE advocates (if not Solis-Garcia himself) seek to purge from the undergraduate curriculum. There always was (and still is) an awareness among structuralists that the economy is made up of parts (households, firms, social classes, markets), and that generalizations about aggregate phenomenon must be accompanied by plausible claims about the behavior of these parts. The argument is that no simple set of relationships links parts and wholes, there being (in particular) no obvious possibility of reducing explanation of the macro whole to its constituent micro parts. Keynes's famous paradox of thrift was an early indication of this, as were the "perverse" macro results that followed from individual firms' behavior in Harrod's dynamics. All of this is now widely recognized as being part of the universe of emergent properties that makes the pursuit of reductionism futile (Setterfield, 2018, p. 239).

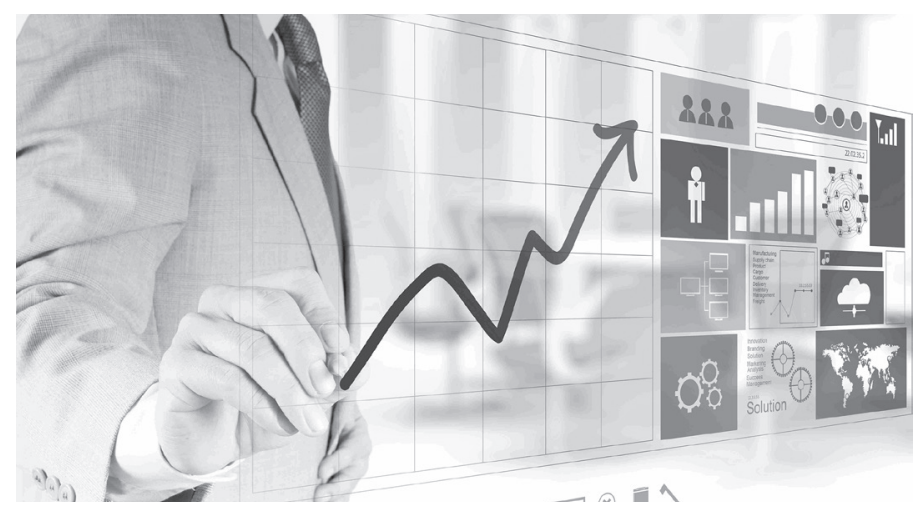




\section{Teaching of DSGE models and pluralism in economics}

The objective in this section is to present an evolutionary model of paradigmatic struggle between two schools within a department of economics (Palley, 1997). The system of equations answers an important question: Why do some ideas expand and dominate economic thought, while others move to the trunk of history courses of economic doctrines? There are two types of economics teachers. The NCs that are the neoclassical and the advocates of introducing the teaching of the DSGE models in the undergraduate programs. PKs are heterodox economists, who defend academic pluralism. The equations are the following:

$$
\begin{aligned}
& S_{t}^{N C}=a S_{t-1}^{N C}+(1-b) S_{t-1}^{P K} \\
& S_{t}^{P K}=b S_{t-1}^{P K}+(1-a) S_{t-1}^{N C}
\end{aligned}
$$

$S_{t}^{N C}$ y $S_{t}^{P K}$ are the participations of the two types of professors-researchers in the total of members of the department. By definition, $S_{t}^{N C}+S_{t}^{P K}=1$.

The parameters of the system are bounded in the following way: $0 \leq a \leq 1$ y $0 \leq b \leq 1$. In the model "a" and "b" represent social practices and the rules of the game in the department. For example, the department promotes pluralism or not, there are controls and filters biased against some group in the publications and financing of research projects or certain courses are privileged over others.

A department that promotes discussion and tolerates the existence of paradigmatic diversity is characterized by having values of "a" and "b" less than 1.

Figure 1 shows the simulation of the interaction of teacher-researchers in an open and tolerant academic world. In the horizontal axis the periods or time are recorded, in the vertical axis the evolution of the percentages of each type of teacher in the total payroll of the department is shown. As can be seen, in the long term the theoretical difference and the pluralistic vision are conserved.
Graphic 1. Pluralist Model Solution

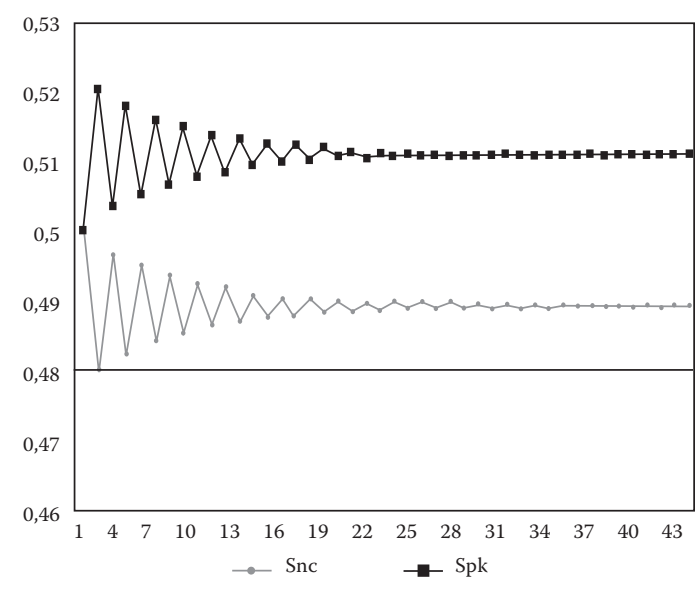

Source: own calculations

When the preferences of the new generations of teachers, educated in the "frontier" of the DSGE models, prevail in the department, not only the correlations of political forces change, but also the rules of the game and the evaluation and promotion criteria are defined over new indicators and directions.

Those who consider that it is necessary to promote and generalize the ideas of the mainstream begin with a kind of parallel action with the aim of reducing the history courses, heterodox economy and related areas, replacing them with "new" courses that are sold as hot potato between the members of the university community, since they are presented as the only way to professional and scientific success. It is repeated without major criteria: The DSGE model is the truth, the way and life itself.

Under these conditions, the parameter "a" is equal to 1 . As shown in figure 2, the consequence of the new academic rules of the game lead to the disappearance of the plurality and diversity of approaches in the department. Only neoclassical teachers-researchers survive. 
Graphic 2. Non-Pluralist Model Solution

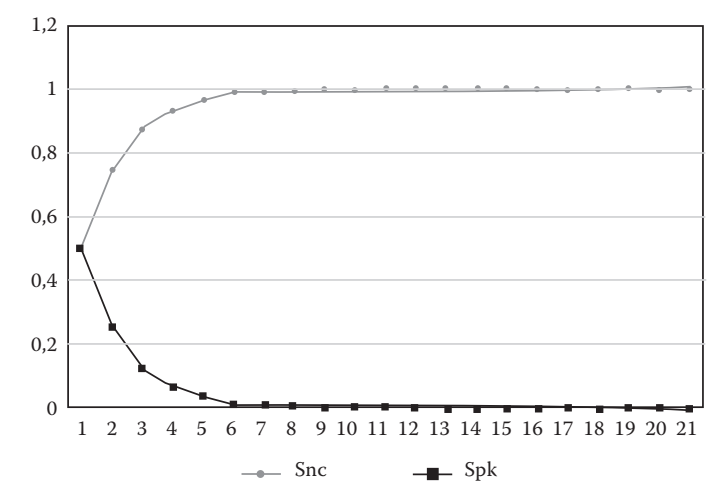

Source: own calculations

\section{Conclusions}

The proposals to introduce advanced courses to teach DSGE models in undergraduate economics in order to bring students to the "frontier" of scientific research may have aggregate consequences for departments that are not deducted from the microeconomic benefits of students and the teachers.

The priority of teaching a mono-culture will end up destroying the pluralistic discussion of the system. Consequently, the critical voices will disappear and the nonsense written in mathematical language will replace the good theories. It is Gresham's law of ideas. Bad models displace good ideas.

As Setterfield (2018) says: "As everyone knows, bad theories lead to bad policies. But perhaps worst of all is that bad theories end up in bad political skills" (p. 239).

\section{Referencias}

Barro, R. (1986). Macroeconomía. México: Interamericana.

Blanchard, O. (2017). Do DSGE models have a future? In Refet S. Gürkaynak and Cédric Tille (Ed). DSGE Models in the conduct of policy. London: CEPR Press.

Costa, C. J. (2016). Understanding DSGE models. Theory and Applications. Malaga: Vernon Press.
Flaschel, P. (2009). The Macrodynamics of Capitalism. Elements for a Synthesis of Marx, Keynes and Schumpeter. Germany: Springer.

Kundera, M. (1981). Jacques y su Amo. Homenaje a Denis Diderot. Madrid: Tusquets Editores.

Haldane, A. \& Turrel, E. A. (2017). An interdisciplinary model for macroeconomics. Staff Working Papers, 6(96). London: Bank of England.

Palley, T. (1997). The Academic Jungle: social practice and the survival of economic ideas. Review of Radical Political Economy, 29(3), 22-33.

Rogers, C. (2008). Money as Friction: Conceptual Dissonance in Woodford's Interest and price. Research Paper, 2008(3).

Rovelli, C. (1999). Quantum spacetime: what do we know'. Marseille. France: Centre de Physique Theorique de Luminy.

Setterfield, M. (2018). Maybe you can, but perhaps you shouldn't!. Saving undergraduate macroeconomics from DSGE modeling. The Journal of Economic Education, 49(3), 237-241.

Smolin, L. (2001). Three roads to Quantum Gravity. New York: Basic Books.

Smolin, L. (2006). Las Dudas de la física en el siglo XXI. ¿Es la teoría de cuerdas un callejón sin salida? Barcelona: Crítica.

Solis-Garcia, M. (2018). Yes we can!. Teaching DSGE models to undergraduate students. The Journal of Economic Education, 49(3), 226-236.

Torres, J. L. (2014). Introduction to Dynamic Macroeconomic General Equilibrium Models. Málaga: Vernon Press.

Veneziani, R. \& Luca, Z. (2018). Analitycal Political Economy. New Delhi, India: Wiley Blackwell.

Williamson, S. (2008). Macroeconomics. New York: Pearson Addison Wesley. 